\title{
Crenças e atitudes linguísticas de descendentes de imigrantes italianos: um estudo em Pinho de Baixo, Irati/Pr
}

pg $101-115$

\author{
Rosana Taís Rossa \\ Loremi Loregian-Penkal
}

\section{Resumo}

Este trabalho tem por objetivo apresentar um recorte dos dados coletados em nossa pesquisa de mestrado que se propôs a investigar as crenças e atitudes linguísticas de descendentes de imigrantes italianos em Pinho de Baixo, zona rural de Irati/PR. Das 30 questões analisadas na dissertação, escolhemos apenas seis para apresentar aqui. Seguindo a linha de pensamento de Balthazar (2016), Botassini (2013), Alkmim (2001), Severo (2014) e outros autores, fizemos um levantamento das crenças e atitudes linguísticas dos moradores da comunidade por meio de entrevistas e questionários. Neste estudo, mostraremos algumas das crenças e atitudes linguísticas manifestadas por nossos informantes e refletiremos como elas interferem na nossa visão de mundo, na avaliação da nossa fala e, principalmente, da fala do outro.

Palavras-chave: Crenças e Atitudes linguísticas; Italiano; Pinho De Baixo, Sociolinguística Variacionista.

\section{BELIEFS AND LINGUISTIC ATTITUDES OF ITALIAN IMMIGRANT DESCENDENTS: A STUDY IN PINHO DE BAIXO, IRATI / PARANÁ STATE}

\begin{abstract}
This study aims to present a fragment of the data collected in our master's research which propounded to investigate the linguistic beliefs and attitudes of descendents of Italian immigrants in Pinho de Baixo community, in Irati, Paraná State. Out of the 30 questions analyzed in the dissertation, we chose six to present here. Following the line of thinking of Balthazar (2016), Botassini (2013), Alkmim (2001), Severo (2014) and other authors, we surveyed the linguistic beliefs and attitudes of community residents through interviews and questionnaires. In this study, we will show some of the linguistic beliefs and attitudes manifested by our informants and reflect about how they interfere in our world view, in the evaluation of our speech and, mainly, in the speech of the other.
\end{abstract}

Kewwords: Beliefs and Language Attitudes; Italian; Pinho De Baixo; Variacionist Sociolinguistics.

\section{Introdução}

Se falar da língua é falar do ser humano, então inevitavelmente esbarramos nas "diferenças". Cada indivíduo tem sua própria identidade, suas características peculiares, heranças de uma formação histórica, social e cultural que o moldam e o definem como parte de um grupo determinado. Botassini (2013) declara que, devido às dimensões territoriais, o Brasil é um país multifacetado, sendo natural que haja 
diferenças étnicas, culturais, religiosas, sociais e, inclusive, linguísticas, permeando seus habitantes. Citando uma pesquisa do Grupo de Trabalho de Diversidade Linguística do Brasil (GTDL), Botassini (2013) afirma que no Brasil são falados aproximadamente 200 idiomas. Mais que isso, dentro de cada idioma podem existir divergências na pronúncia das palavras, nas construções sintáticas e nos efeitos de sentido. De acordo com a autora,

verifica-se, no âmbito da própria língua
portuguesa brasileira, variação linguística
decorrente de diferenças regionais ou
geográficas, condicionada pela adequação
do uso da linguagem às diversas situações
comunicativas e sociais, pela faixa etária, pelo
sexo pelo grau de escolaridade dos indivíduos,
dentre outras razões (BOTASSINI, 2013, p.
18).

Além disso, apesar do discurso "monolíngue" que vem sendo propagado há anos aos brasileiros, dentro de uma mesma cidade pode haver realidades linguísticas distintas, mostrando que a diversidade linguística é inerente à linguagem. Um exemplo dessa diversidade linguística está em Irati/PR. Constituída por imigrantes de vários países, entre eles Ucrânia, Polônia e Itália, a cidade é um misto de etnias. Todavia, apesar de a cultura eslava predominar, os descendentes de italianos também representam uma grande parcela da população.

Nazona rural de Irati localiza-se a comunidade do Pinho de Baixo, formada por aproximadamente 150 famílias, em torno de 500 pessoas, e que tem a maioria da população de descendentes de italianos. Antigamente, os habitantes do lugar falavam muito mais em italiano que em português, porém, com o passar do tempo muitos jovens e adolescentes foram estudar na zona urbana, misturando valores e costumes do campo e da cidade que provavelmente influenciaram na língua falada pelos habitantes da comunidade.

O corpus deste estudo é composto por vinte e quatro informantes, sendo que destes: oito possuem menos de quarenta e cinco anos; oito possuem entre quarenta e seis até sessenta e cinco anos; e os demais apresentam idades acima de 66 anos. A escolaridade dos entrevistados se divide em: Ensino Fundamental Incompleto, com 13 informantes; Ensino Fundamental Completo, com 2 informantes; Ensino Médio, com 3 informantes; e Ensino Superior com 6 informantes. Foram entrevistadas 18 mulheres e 6 homens. Os critérios e justificativa para essas escolhas serão apresentadas e discutidas na metodologia. Para fundamentar este trabalho, refletiremos acerca da língua e suas variações, e as crenças e atitudes linguísticas, à luz de pesquisadores relevantes nessas áreas.

\section{Língua e variação}

Uma das primeiras competências desenvolvidas pelo ser humano é a linguagem. Por isso, não seria exagero afirmar que somos movidos pela interação. Para Trudgill (1974), a linguagem é um meio não só de trocar ou transmitir informações, mas sim de interagir, estabelecer e manter relações entre as pessoas. Assim, mais importante que o assunto da conversa é o ato de comunicar, pois a comunicação é uma necessidade natural dos seres humanos.

Acerca das multifuncionalidades da língua, Orlandi declara que

Se a língua não é mais vista apenas como
instrumento do pensamento, como nos
formalistas mais ortodoxos, vai-se percebendo
que ela também não serve só para transmitir
informações, como poderiam deixar crer
os que trabalham a linguagem enquanto
comunicação. Quando os homens se
comunicam, eles fazem muito mais do que
apenas informar (ORLANDI, 2007, p. 54).

Alkmim (2001) explicita a concepção de língua apresentada por Saussure. Para ele, nas palavras da autora,

a língua é um fato social, no sentido de que é um sistema convencional adquirido pelos indivíduos no convívio social. (...) Em consequência, a língua se caracteriza por ser 'um produto social da faculdade da linguagem'. (Alkmim, 2001, p. 23). 
Dessa forma, podemos observar que é na sociedade que a língua se firma enquanto meio de comunicação. Pensando no convívio social, é evidente que o emprego da língua receba influência do contexto que a cerca. Alkmim (2001) assinala uma relevante consideração de Benveniste a respeito disso ao dizer que

\begin{abstract}
A língua permite que o homem se situe na natureza e na sociedade; o homem 'se situa necessariamente em uma classe, seja uma classe de autoridade ou classe de produção'. Em consequência, a língua, sendo uma prática humana, 'revela o uso particular que grupos ou classes de homem fazem dela e como as diferenciações que daí resultam no interior de uma língua comum' (ALKMIM, 2001, p. 27).
\end{abstract}

A língua existe para que possamos dialogar com outras pessoas, trocar ideias, exprimir nossos sentimentos, reivindicar nossos direitos, se fazer ouvir na sociedade, enfim, ela é fundamental na vida humana e tem sido alvo de profundos e representativos estudos.

Partindo da constatação da impossibilidade de separar língua e sociedade, Monteiro (2000) destaca que a função primordial da língua é a comunicação. Assim, como já dito anteriormente, podemos compreender a língua não apenas como um meio de interação, mas sim como uma ponte pela qual valores, conhecimentos e a cultura de uma comunidade são transmitidos de uns indivíduos para outros. Através dela, também, um sujeito se posiciona no mundo, existe e transmite seus pensamentos e suas intenções.

Já sabemos que as línguas são heterogêneas. Isso significa que em qualquer língua há diferentes formas de se dizer a mesma coisa, dependendo de fatores internos e externos a ela. Essa versatilidade é chamada de variação. Coelho et. al (2010) definem variação como

o processo pelo qual duas formas podem ocorrer no mesmo contexto linguístico com o mesmo valor referencial, ou com o mesmo valor de verdade e com o mesmo significado. Dois requisitos devem, pois, ser cumpridos para que ocorra variação: as formas envolvidas precisam ser intercambiáveis no mesmo contexto e manter o mesmo significado (COELHO et. al, 2010, p. 23)
Consoante Mollica (2009), a língua quando empregada nas situações cotidianas é heterogênea e variável. De acordo com a perspectiva da Sociolinguística, essa variação é promovida por fatores classificados em dois grandes grupos: o linguístico, no qual figuram condicionantes fonéticos, morfológicos, sintáticos, semânticos ou discursivos; e o extralinguístico, como nível de escolaridade, sexo, idade, condições socioeconômicas, particularidades regionais, entre outras.

Em nossa sociedade, cada grupo social pode ser identificado por características próprias. Os trajes, as músicas que ouvem e o jeito de andar e se comportar denunciam em que espaço social esses sujeitos se inserem. Com a fala não é diferente. Alkmim (2001) escreve acerca das comunidades linguísticas, que nada mais são do que grupos sociais que ao ocuparem um espaço assumem uma forma própria de falar que os diferem dos outros grupos.

A variedade linguística que utilizamos diz muito sobre nós e sobre a nossa cultura, principalmente no que tange ao contexto social, familiar e regional em que estamos inseridos, bem como no tocante às relações que estabelecemos com o mundo à nossa volta. Aguilera e Silva (2014, p. 705) reforçam a importância da língua para nos identificar socialmente ao afirmarem que "além de fazer parte da constituição do indivíduo, a língua ou o dialeto utilizado por ele pode integrá-lo, valorizálo, discriminá-lo ou elevá-lo socialmente”.

Podemos reforçar, então, que o sujeito é fruto do meio. Ou seja, é a partir das interações que o sujeito elegerá, inconscientemente, a variedade linguística que fará uso e será essa variedade, muito provavelmente, que ele manterá ao longo da vida.

\section{Crenças e atitudes linguísticas}

Desde muito cedo somos moldados para convivermos em sociedade. Aprendemos muitas 
regras de comportamento, ouvimos inúmeras orientações sobre como tratar os mais velhos, de que forma usar os pronomes de tratamento e mais uma imensidade de coisas. $\mathrm{O}$ mesmo acontece com a nossa fala.

Mollica (2009) acentua que já na infância os usuários da língua se deparam com uma série de crenças e atitudes relacionadas à língua. Assim, tomam conhecimento de que há maneiras certas e erradas, bonitas e feias de se falar uma língua, propiciando uma atmosfera adequada para que os juízos de valor sobre a linguagem individual se constituam. Os sujeitos

\begin{abstract}
adquirem, portanto, um saber, sistematizado ou não, a respeito da sua própria língua que lhes permite reconhecer que um determinado falante "não é daqui", ou "fala errado", ou "tem baixo nível cultural", enfim, um saber que lhes permite estabelecer e assumir determinadas identidades sociais a partir dos diferentes usos linguísticos. (MOLLICA, 2009, p. 86).
\end{abstract}

Quando optamos por determinada variante durante nossa fala, somos submetidos a um julgamento pela sociedade. Por meio das nossas escolhas lexicais e da maneira como construímos nosso discurso, nosso interlocutor pode tecer diversas interpretações sobre quem somos, de onde viemos, o que fazemos e o que sabemos. A fala é carregada de identidade, e a variante que escolhemos para cada contexto da nossa vida pode nos expor. Para Alkmim

\begin{abstract}
Cada grupo social estabelece um contínuo de situações cujos polos extremos e opostos são representados pela formalidade e informalidade. (...) As variedades linguísticas utilizadas pelos participantes das situações devem corresponder às expectativas sociais convencionais: o falante que não atender às convenções pode receber algum tipo de "punição", representada, por exemplo, por um franzir de sobrancelhas. (ALKMIM, 2001, p. 37).
\end{abstract}

Os fatores sociais interferem no nosso exercício da linguagem, ou seja, elementos externos à língua influenciam a nossa forma de falar. Acerca disso, a autora supracitada afirma que "no ato de interagir verbalmente, um falante utilizará a variedade linguística relativa a sua região de origem, classe social, idade, escolaridade, sexo etc. e segundo a situação em que se encontrar" (ALKMIM, 2001, p. 39).

É evidente que a classe social dominante sempre terá privilégios. Um deles é ter sua variedade linguística estabelecida como padrão. Tornou-se muito comum vermos as pessoas querendo "falar bonito" na intenção de demonstrar pertencer a uma classe mais elevada socialmente. Dessa forma, percebe-se que o valor de uma variedade linguística é igualmente proporcional ao valor dos seus usuários. Acerca disso, Bagno declara que

(...) quanto mais alto estiver a pessoa na
escola socioeconômica (e também quanto
mais elevado for o seu grau de escolarização),
maior será o prestígio atribuído a sua maneira
de falar. Do mesmo modo, e inversamente,
o menor prestígio social de determinados
falantes vai ser correlato da visão pejorativa e
depreciativa com que seu modo de falar será
avaliado. (BAGNO, 2007, p. 77 ).

Para discutirmos as crenças e atitudes linguísticas de uma comunidade da zona rural de Irati, é necessário fazermos uma contextualização espacial geral do nosso estado, para que compreendamos os fenômenos que contribuem para que haja tamanha variedade de falantes. Para tanto, ecoaremos as palavras de Corbari (2012):

"O Estado do Paraná, graças à colonização
por descendentes de imigrantes de diversas
etnias e aos contatos estabelecidos nas regiões
fronteiriças a países hispano-americanos,
apresenta um cenário sociolinguístico
complexo que propicia o estudo tanto das
línguas em contato quanto das crenças e
atitudes relacionadas a essas línguas e a
seus usuários, já que tal cenário favorece
manifestações tanto positivas (prestígio
linguístico) quanto negativas (desprestígio
linguístico) dos informantes frente aos falares
locais". (CORBARI, 2012, p. 112).

Considerando a intensa imigração que ocorreu em nosso estado e ao fazermos uma breve reconstituição histórica da formação de Irati, vemos que muitos imigrantes provenientes da Holanda, 
Polônia, Ucrânia, Alemanha e Itália se instalaram nas redondezas da cidade, estabelecendo novas relações e propagando suas culturas. Isso explica as diversas colônias que podem ser percebidas por toda a nossa região.

Devido a essa grande variedade de falares, é natural que alguns indivíduos julguem sua língua superior ou inferior às outras. Pensar que a forma como falamos é melhor que de outras pessoas constitui uma crença. Agir com intolerância, desprezo ou tentar camuflar a própria língua pode ser definido como uma atitude.Para Aguilera e Silva (2014),

\begin{abstract}
"A relevância que as crenças e as atitudes linguísticas possuem hoje deve-se ao fato amplamente disseminado de que existem línguas, dialetos e variedades que representam classes sociais mais elevadas ou prestigiadas, característica que a elas atribui, na maior parte das vezes, um lugar privilegiado na escala social, ou seja, maior status. Dentre tantos, podemos citar como exemplos a língua inglesa, idioma universalmente conhecido e ensinado e a variedade padrão da língua portuguesa, forma eleita como própria daqueles que estão alocados em uma escala social mais bem conceituada". (AGUILERA E SILVA 2014, p. 707).
\end{abstract}

Antes de prosseguirmos, nos convêm esclarecer por que optamos por distinguir, neste estudo, crenças de atitudes. Em primeiro lugar, apresentamos nossa concepção de crença como uma opinião, ou seja, um ponto de vista, uma concepção acerca de um tema ou assunto. A atitude, por sua vez, é caracterizada como um comportamento, uma ação ou uma prática que, geralmente, é consequência de algo pensado consciente ou inconscientemente.

Quando temos uma opinião em relação a algo, tendemos a nos comportar consoante a essa opinião, mas essa não é uma regra. Em alguns casos, seja por educação, bom senso, ou para praticar o politicamente correto, agimos de uma forma que nega nossa real avaliação do que nos é exposto. Quando, por exemplo, um amigo que canta mal, mas está empolgadíssimo para participar de uma competição de música, pergunta nossa opinião sobre sua voz e afinação, para não desanimá-lo garantimos que ele é sensacional como cantor. Nesse caso, nossa crença não está sendo externada em nossa atitude, o que confirma a tese de que elas se complementam, mas não são indissociáveis.

Assim, considerando que a atitude consiste em uma reação a coisas, pessoas e fatos, e crenças como aquilo que acreditamos ser certo ou errado, bonito ou feio etc., estabelecemos relações entre esses conceitos e o conceito de preconceito linguístico, pois depreendemos que é a partir desses dois elementos que os sujeitos podem ter atitudes preconceituosas em relação à língua ou à variação empregada pelo outro. Reiteramos, portanto, que apesar de muitos pesquisadores estudarem crenças e atitudes como ideias imbricadas, neste trabalho as abordaremos separadamente.

Para Souza (2012), o gesto de escolher uma língua para nos comunicarmos já constitui uma atitude linguística. Quando elegemos um objeto, assumimos muitas crenças a respeito dele, atribuindo características diferentes, como valores e conceitos. A crença pode, então, se relacionar com diferentes aspectos de uma situação, implicando em atitudes que transparecerão essas crenças. De acordo com Massarolo (2012, p. 4), “podemos afirmar que o falante possui crenças valorativas em relação ao mundo e, consequentemente, sua conduta será condizente com esse saber ou crença, uma vez que são estímulos reforçados pelo meio".

Para Botassini (2013), muitas áreas do conhecimento utilizam a palavra crença para discutir questões relevantes para si e por isso torna-se difícil dar uma definição específica e fixa a ela. Para tentar explicar com mais respaldo acerca desse vocábulo, vamos às definições dadas por pesquisadores da área.

Barcelos (2006, apud CARRARO, 2016) declara que as crenças são 
uma forma de pensamento, construções da realidade, maneiras de ver e perceber o mundo e seus fenômenos, co-construídas em nossas experiências resultantes de um processo interativo de interpretação e (re) significação. Como tal, crenças são sociais (mas também individuais), dinâmicas, contextuais e paradoxais (BARCELOS, 2006 apud CARRARO, 2016, p. 38).

Acerca das crenças, Santos (1996 apud Cyranka, 2007) apresenta a seguinte concepção:

Crença seria uma convicção íntima, uma opinião que se adota com fé e certeza.[...] Já atitude seria uma disposição, propósito ou manifestação de intento ou propósito. Tomando atitude como manifestação, expressão de opinião ou sentimento, chegase à conclusão de que nossas reações frente a determinadas pessoas, a determinadas situações, a determinadas coisas seriam atitudes que manifestariam nossas convicções íntimas, ou seja, as nossas crenças em relação a essas pessoas, situações ou coisas (SANTOS (1996, apud CYRANKA, 2007, p. 22) .

Ter uma crença sobre uma língua implica em uma série de ações que praticamos em menção a ela. A forma como falamos, as escolhas lexicais que fazemos e, principalmente, nosso posicionamento perante a língua do outro, refletem não apenas nossos preconceitos, como também nossa identidade.

Para os pesquisadores canadenses William e Wallace Lambert, o estudo das atitudes é relevante porque "trata de um complexo fenômeno psicológico que se reveste de um tremendo significado social" (LAMBERT e LAMBERT, 1968, p. 77). Para os autores, as atitudes podem ser definidas como

uma maneira organizada e coerente de pensar, sentir e reagir em relação a pessoas, grupos, questões sociais ou, mais genericamente, a qualquer acontecimento ocorrido em nosso meio circundante. Seus componentes essenciais são os pensamentos e as crenças, os sentimentos (ou emoções) e as tendências de reagir. (LAMBERT e LAMBERT, 1968, p. 77 e 78).

Segundo esses pesquisadores, desenvolvemos as atitudes numa tentativa de nos ajustarmos à determinada situação social. A princípio, quando estamos elegendo as atitudes, novas experiências podem modificá-las. Todavia, quando elas já estão definidas, passamos a utilizá-las regularmente, tornando-as fixas. Assim, é muito comum que as pessoas fiquem presas a essas concepções, "de modo que fiquem incapacitadas para examinar ou reconhecer a individualidade dessas mesmas pessoas ou eventos" (LAMBERT e LAMBERT, 1968, p. 78).

Os falantes de uma língua têm, como já mencionado, atitudes em relação à própria língua e à língua dos outros. Essas atitudes, segundo Frosi, Faggion e Dal Corno (2010, apud Aguilera e Silva, 2014, p. 708) podem ser interpretadas como “(...) uma postura, ou comportamento positivo ou negativo frente a uma língua ou a uma variedade linguística particular, uma reação favorável ou desfavorável face ao modo de falar do outro". Calvet (2002, p. 65), por sua vez, declara que "as atitudes linguísticas exercem influências sobre o comportamento linguístico".

Sobre os juízos de valor, Balthazar considera que

ao ouvir a língua de um grupo, o ouvinte reage de forma a atribuir valores a ela e aos seus falantes. De fato, a forma de falar de uma pessoa ou de um grupo vai interferir nas avaliações que são feitas sobre esse grupo por outras pessoas (BALTHAZAR, 2016, p. 18).

Balthazar (2016) reforça a pertinência da fala na caracterização de um sujeito como indivíduo e como membro da sociedade. De acordo com a pesquisadora
a fala pode revelar muito sobre o falante: sua proveniência, faixa etária, classe sociocultural etc. Certamente a língua é um dos símbolos externos mais perceptíveis de um grupo, isso porque, quando falamos, somos facilmente reconhecidos - ou não - como membros pertencentes a um grupo. (BALTHAZAR, 2016, p. 18).

Em relação a como as atitudes podem ser, a autora reitera que há três opções: negativas, 
positivas e neutras. Sobre as negativas, citando Moreno Fernández (1998), Balthazar (2016) afirma que

A atitude linguística pode ser negativa em relação à sua própria língua, por exemplo, quando essa variedade não permite aos seus falantes ascensão social, melhora econômica ou mobilidade em outros lugares diferentes dos seus. (BALTHAZAR, 2016, p. 23).

Já acerca das atitudes linguísticas positivas, retomando os conceitos de Moreno Fernández (1998), a pesquisadora explica que

\begin{abstract}
Por outro lado, as atitudes linguísticas podem ser positivas em relação à língua, e elas são, geralmente, sobre a fala dos grupos sociais mais poderosos socioeconomicamente. Isso porque atitudes são, frequentemente, manifestação de uma preferência e convenção social sobre o status e o prestígio dos falantes. (BALTHAZAR, 2016, p. 23).
\end{abstract}

Weinreich (1974, apud BALTHAZAR, 2016) chama a atitude linguística positiva de fidelidade linguística. É essa fidelidade que nos move a querermos proteger nossa língua do declínio. Para esse autor,

\begin{abstract}
a fidelidade linguística poderia ser definida como um princípio [...] no qual as pessoas empenham a si mesmas e os outros falantes conscientemente e explicitamente a resistir a toda mudança no funcionamento, na estrutura e no vocabulário da língua (WEINREICH, 1974, apud BALTHAZAR, 2016, p. 24).
\end{abstract}

Há, por fim, a atitude neutra, ou seja, aquela em que o falante não apresenta atitude negativa nem positiva, ficando no meio termo. Alguns autores negam que exista essa categoria para as atitudes, mas Balthazar (2016), Carraro (2016) e Souza (2012) consideram essa categorização.

Com base nessas leituras, pudemos perceber que há uma linha muito tênue que separa as atitudes diante de uma língua das atitudes diante de um grupo social. Rodrigues (2012) propõe a seguinte reflexão:
As atitudes linguísticas são atitudes psicossociais, ou seja, se as línguas têm conotações sociais, é natural que sejam avaliadas (admiradas ou desprezadas) a partir do status ou das características sociais dos seus usuários. Por isso, a atitude em relação a uma língua e a atitude em relação ao grupo social que dela se serve parecem confundir-se (RODRIGUES, 2012, p. 363).

Quando ouvimos um falante dizendo caroça enquanto dizemos carroça, imediatamente reconhecemos que há uma diferença na fala dele quando comparada à nossa. Esse é o primeiro reflexo. Consequentemente, imaginamos que esse sujeito vem de outra região e tem outra cultura. Nesse momento, com base em nossas vivências sociais, "julgamos" esse falante a partir da sua fala e o consideramos inferior, superior ou igual a nós, reagindo com desprezo, reverência ou indiferença. É assim que nossas atitudes linguísticas se confundem com as atitudes em relação ao falante e ao grupo social a que ele pertence.

Fica evidente aqui que a condição social de um grupo pode ser totalmente refletida na linguagem empregada por ele e vice-versa. Há uma preocupação muito grande em se extinguir vários tipos de preconceitos, mas o olhar com desprezo para um falante que fala diferente ou usa termos e palavras pouco ou nada utilizadas por nós é pouco debatido. Por isso reiteramos a relevância dos estudos que abordam o preconceito linguístico, sempre relembrando que atitudes positivas, negativas ou neutras em relação ao falar do outro podem afetar diretamente no seu interior, colocando em cheque sua identidade.

De acordo com importantes pesquisadores de crenças e atitudes, citados por Botassini (2013), há três componentes agregados às atitudes linguísticas: cognitivo, afetivo e comportamental. O primeiro deles é o componente cognitivo. Segundo a pesquisadora, ele diz respeito às crenças e pensamentos que temos em relação a um objeto que conhecemos. O 
componente afetivo está relacionado às emoções e sentimentos acerca de determinado objeto. Por fim, há o componente comportamental, definido como conduta ou reação a um objeto.

No que tange à manutenção da cultura e da língua italiana na comunidade estudada, mencionamos brevemente os conceitos de lealdade e deslealdade linguística. Consoante Botassini (2013), a atitude de um falante frente ao seu grupo linguístico pode ser positiva ou negativa, revelando um ato de lealdade ou deslealdade linguística, respectivamente.

É interessante salientar que um falante pode ter atitudes diferentes em relação à sua língua dependendo do contexto e da posição que ele ocupa em determinados momentos. Isso significa que em certos lugares podemos ostentar tranquilamente nosso sotaque, mas em outras ocasiões há a possibilidade de ocultarmos nosso vernáculo. Para Balthazar (2016, p. 26), é “a mesma língua, com o mesmo indivíduo, mas com atitudes opostas de acordo com o momento e o papel desenvolvido na sociedade".

\section{Corpus e metodologia de pesquisa}

Esta pesquisa foi desenvolvida com base nos pressupostos da Sociolinguística Variacionista e nos estudos sobre Crenças e Atitudes linguísticas. Consideramos, para tanto, que a língua é um fato social, que abrange não apenas fatores internos à própria língua, mas também fatores sociais, que permitem que a língua se manifeste na sociedade, permitindo aos seus usuários que construam sentido a partir dela e estabeleçam, assim, suas relações.

A comunidade pesquisada foi escolhida por estar situada na zona rural de Irati/PR e apresentar como seus constituintes descendentes de italianos que têm buscado, de diferentes formas, manter vivas as tradições que herdaram dos antepassados. Embora já bastante afetada pela modernidade da cidade, a comunidade vem se mostrando decidida a deixar para os mais novos a língua e a cultura que herdaram dos pais. Por meio do museu, do grupo de cantos e danças e da Festa da Polenta, muitos jovens estão se engajando na missão de consolidar a língua italiana falada na comunidade.

Um dos maiores motivos de orgulho para os moradores do Pinho de Baixo é o "Grupo Folclórico Chiaro di Luna”. Semanalmente, acontecem reuniões do grupo nas quais os integrantes aprendem o idioma italiano, danças, músicas, gastronomia típica, bordados, costura e outros aspectos da cultura italiana. Segundo Bacil (2012),

Os componentes do grupo Chiaro di Luna,
devidamente vestidos com trajes típicos,
já se apresentaram em diversos eventos,
com número de danças e interpretaçóes de
músicas folclóricas, populares e religiosas na
localidade, na cidade de Irati, na região e em
diversas cidades do Paraná e de Santa Catarina.
O grupo, além de expandir a tradição italiana,
tem conseguido estreitar laços de amizade,
desenvolver o espírito de colaboração entre
seus componentes e a comunidade em geral
(BACIL, 2012, p. 112).

O idioma italiano estudado no curso foi muito debatido durante as entrevistas, isto porque muitos dos falantes não reconhecem esse dialeto como sendo o que eles ouviam em casa, com os pais e avós. De acordo com alguns informantes, a língua estudada é o padrão da Itália e é bem diferente da que eles conhecem.

Quando o grupo começou, a ideia era apenas conhecer mais sobre a língua e, por isso, os materiais utilizados eram, em sua maioria, músicas e rezas. No decorrer das aulas, o professor Edson Moro Rios, que é o presidente do grupo, percebeu que havia afinação nas vozes dos adultos e das crianças, e por isso decidiram criar o grupo de canto.

Uma casa de madeira no mesmo estilo das casas construídas pelos imigrantes italianos foi construída no centro da comunidade para abrigar um museu da cultura italiana. Nesse espaço é possível encontrar diversos objetos pertencentes 
aos imigrantes, bem como trajes, fotografias e equipamentos de trabalho. Anualmente, a comunidade promove a Festa da Polenta, importante evento que reúne mais de 500 pessoas para prestigiar as comidas, os vinhos, as músicas e danças típicas dos italianos. Por meio desses recursos, o Pinho de Baixo busca preservar a cultura daqueles que contribuíram para a consolidação e manutenção da comunidade.

A capela São Sebastião foi construída em 1912 e, em 2012, para comemorar o seu centenário, foi lançado um livro sobre a história da comunidade de Pinho de Baixo. Atualmente, a população da comunidade consiste em 150 famílias, totalizando, aproximadamente, 500 pessoas.

Para realizar nossa pesquisa, selecionamos vinte e quatro informantes, todos residentes na localidade de Pinho de Baixo, zona rural de Irati/Pr. A princípio, nosso intuito era dividir os entrevistados em quatro grupos de seis informantes, cada grupo pertencente a um grau de escolaridade: Ensino Fundamental, Ensino Médio, Ensino Superior e Analfabetos. Porém, ao fazermos um levantamento inicial dos moradores, constatamos que não há nenhum descendente de imigrantes italianos na comunidade que não tenha frequentado ao menos a primeira série do Ensino Fundamental. Portanto, não tínhamos analfabetos para entrevistarmos. Nosso critério então mudou, e dividimos os informantes em Ensino Fundamental Incompleto, Ensino Fundamental Completo, Ensino Médio e Ensino Superior.

No entanto, mais uma vez encontramos dificuldades para adequar os entrevistados nas escolaridades de forma padronizada. Não tínhamos seis informantes para cada categoria, por isso, decidimos realizar a pesquisa com os que tinham disponibilidade e, acima de tudo, forte envolvimento com a cultura italiana. Como nosso objetivo era conhecer e investigar as crenças e atitudes linguísticas, selecionamos descendentes que apresentaram interesse em falar sobre a língua e a cultura italiana, bem como seu interesse em mantê-las vivas na localidade. Assim, no critério escolaridade, nossos entrevistados consistem em: 13 falantes com Ensino Fundamental Incompleto; 2 com Ensino Fundamental Completo; 3 com Ensino Médio e 6 com Ensino Superior.

No tocante à variável sexo, esperávamos encontrar doze informantes do sexo masculinos e doze do sexo feminino, mas também não foi possível. Entrevistamos dezoito mulheres e seis homens. Isso ocorreu porque, em geral, as meninas é quem ficavam em casa com a mãe enquanto o pai e os filhos iam para a roça. Por passar mais tempo com as filhas, as mães ensinavam para elas a língua, as rezas e cantos em na língua italiana.

Entre nossos critérios para a seleção dos entrevistados não estava o de que todos os sujeitos falassem ou soubessem a língua italiana, e sim que tivessem algum envolvimento com essa língua dentro de casa ou em outro contexto em que convivem, buscando preservá-la. Alguns possíveis informantes dos quais nos aproximamos não esboçaram desejo em falar sobre a língua e sua relevância para a comunidade, alegando não ter conhecimento ou envolvimento o suficiente para tanto. Por isso há essa disparidade no número de conhecedores e falantes da língua, o que, consequentemente, reduziu o número de informantes do sexo masculino para esta pesquisa. Consideramos importante a discussão das variáveis sexo e escolaridade dentro de uma pesquisa Sociolinguística, já que é possível perceber as marcantes diferenças na fala de homens e mulheres, bem como de pessoas com mais ou menos estudo, pois sabemos que esses fatores definem a variante empregada pelo falante. Entretanto, esclarecemos que, embora citaremos essas variáveis (sexo e escolaridade) durante nossa pesquisa e exposição dos dados, não as utilizaremos como parâmetro de análise, já que não obtivemos 
números representativos e padronizados para tais comparações.

Em relação à faixa etária, dividimos os entrevistados em três grupos de idades diferentes, sendo 8 abaixo de 45 anos; 8 entre 46 e 65 anos; e 8 acima de 66 anos.

Por meio dessa divisão da faixa etária, buscaremos compreender se ocorre e de que maneira ocorre a manutenção ou o abandono da língua italiana por parte dos descendentes de italianos moradores do Pinho de Baixo.

Apresentaremos na tabela 1 a lista com o número de identificação e os dados mais relevantes dos entrevistados.

\begin{tabular}{|c|c|c|c|c|c|}
\hline Informentes & Escolaridade & $\begin{array}{l}\text { Profindo/ } \\
\text { Ocupacio }\end{array}$ & Idade & Sexo & Ermia \\
\hline Informame 1 & E. F. incompleto & Agriculsoma & 60 & $F$ & Italiana \\
\hline Informame 2 & E. F. incomplets & Agriculsoma & 59 & $F$ & $\begin{array}{l}\text { Italiana } \\
\text { na }\end{array}$ \\
\hline Informane 3 & E. F. incompleto & Agriculsoma & 90 & $F$ & Italiana \\
\hline Informante 4 & E. F. incomplets & Agriculioma & 75 & $F$ & Italiana \\
\hline Informante 5 & E. F. incomplets & Do lar & 68 & $F$ & Italiana \\
\hline Informande 6 & E. F. incomplets & Agricultoe & 74 & $\mathrm{M}$ & Italiana \\
\hline Informante? & E. F. incompleto & Agricultoer & 59 & $\bar{M}$ & Italiana \\
\hline Informante 8 & E. F. incompleto & Agricultore & 57 & $\mathrm{M}$ & Italiana \\
\hline Informante 9 & E. F. incomplets & Agricultoe & 64 & $\bar{M}$ & Italiana \\
\hline Informante 10 & E. F. incomplets & Agricultor & 86 & $\mathrm{M}$ & Italiana \\
\hline Informanie II & E. F. incomplets & $\begin{array}{l}\text { Agniculsomal } \\
\text { costureira }\end{array}$ & 90 & $F$ & Italiana \\
\hline Informante 12 & E. F. incompleto & Agricultoe & 76 & $\bar{M}$ & Italiana \\
\hline Informante 13 & E. F. incomplets & Do har & 77 & $F$ & Italiana \\
\hline Informane 14 & E. F. completo & Agriculsona & 63 & $F$ & Italiana \\
\hline Informante 15 & E. F. completo & Aposentada & 65 & $\mathrm{~F}$ & Italiana \\
\hline Informante 16 & EM. & Agriculiona & 38 & $F$ & Italiana \\
\hline Informante 17 & EM. & Autbooma & 31 & $F$ & Italiana \\
\hline Informane 18 & EM. & Agriculiona & 55 & $\mathrm{~F}$ & Italiana \\
\hline Informante 19 & E.S. & Do lar & 29 & $F$ & $\begin{array}{l}\text { Italiana } \\
\text { (n) }\end{array}$ \\
\hline Informante 20 & E.S. & Professora & 32 & $\mathrm{~F}$ & Italiana \\
\hline Informante 21 & E.S. & Estudante & 22 & $F$ & $\begin{array}{l}\text { Italiana } \\
\text { nat }\end{array}$ \\
\hline Informante 22 & E.S. & Analista comercial & 25 & $F$ & Italiana \\
\hline Informante 23 & E.S. & Professora & 45 & $F$ & $\begin{array}{l}\text { Italiainal } \\
\text { polooots }\end{array}$ \\
\hline Informante 24 & E.S. & Agriculasona & 28 & $F$ & Italiana \\
\hline
\end{tabular}

Tabela 1: Dados sobre os entrevistados

Temos, portanto, dos 24 entrevistados, 18 mulheres e 06 homens, sendo que a maioria dos entrevistados possui mais de 46 anos. Apesar de grande parte se declarar agricultor, há ainda as profissões de costureira, professora e analista comercial. Esse é o perfil majoritário do nosso corpus.

\section{Apresentação e análise dos dados}

Quando falamos, estamos indo muito além da transmissão de uma mensagem. Brandão (1991) declara que ao falarmos deixamos transparecer várias características da nossa identidade, o que oferece condições para que nosso interlocutor nos filie em determinado grupo social. De acordo com a autora,

A entonação, a pronúncia, a escolha vocabular, a preferência por determinadas construções frasais, os mecanismos morfológicos que the são peculiares podem servir de índices que identifiquem: o país ou a região de que se origina; o grupo social de que faz parte (seu grau de instrução, sua faixa etária, seu nível socioeconômico, sua atividade profissional); e a situação (formal ou informal) em que se encontra (BRANDÃO, 1991, p. 6).

Ao analisarmos os dados coletados em nossa pesquisa, veremos de que forma a fala deixa transparecer essas características tão peculiares de cada falante.

As três primeiras perguntas que exporemos aqui são voltadas para as crenças linguísticas. A primeira delas é: "Você acha que homens e mulheres falam da mesma forma ou falam diferente"? As respostas foram as seguintes:

\begin{tabular}{|c|c|c|}
\hline Informantes & Percebe diferença & Não percebe diferença \\
\hline Abaiixo de 45 anos & $(16)(19)(20)(21)(22)(24)$ & $(1)(17)(23)$ \\
\hline Entre 46 e 65 anos & $(2)(18)$ & $(7)(8)(9)(14)(15)$ \\
\hline Acima de 66 anos & $(11)$ & $(3)(4)(5)(6)(10)(12)(13)$ \\
\hline Total: & 9 & 15 \\
\hline
\end{tabular}

Tabela 2: Percepção das diferenças entre a fala de homens e mulheres

Ao contrário do que suspeitávamos, a maioria dos informantes afirmou que homens e mulheres têm o mesmo jeito de falar. Dentre os 24 entrevistados, 15 asseveraram que a entonação da voz é o que mais se destaca na fala dos italianos, já que estes têm um jeito peculiar de falar, mais forte 
e mais alto que as demais etnias e isso se aplica tanto aos homens quanto às mulheres:

Os descendentes de italiano sempre são... mais assim, falam forte, né?... já é o costume do italiano né?, tanto homem quanto mulher falam forte (Informante 1, feminino, 60 anos).

Conversam sempre na mema cantoria, como diz o causo (Informante 10, masculino, 86 anos).

Ah, tudo os italianos falam mais agitado, mais com as mão (Informante 17, feminino, 37 anos)

Não, só o timbre, o sotaque e o jeito de falá é o mesmo pra tudo mundo (Informante 16, feminino, 38 anos)

Os outros 09 entrevistados asseguram que há, sim, disparidades nas falas de homens e mulheres. Para eles:

Eu acho que tem diferença. Mulher é mais dócil pra falá, né... homem às vezes vai meio na... (Informante 2, feminino, 59 anos)

As mulher falam mais braba (Informante 11, feminino, 90 anos)

Pois é, eu acho que os homens já são mais assim, falam mais com as mãos, com os gesto, e as mulheres já não (Informante 18, feminino, 55 anos).

Ah, homem é mais certero, né? Mais direto e a mulher começa a falá mais um pouquinho (Informante 19, feminino, 29 anos).

Os homens, eles têm assim uma linguagem... não só a linguagem, mas a maneira de ser diferente das mulheres... as mulheres são mais recatadas (...) eu vejo muita diferença (Informante 20, feminino, 32 anos).

Falam diferente... é bem diferente (Informante 24, feminino, 28 anos).

Acerca das semelhanças e diferenças na linguagem dos falantes, questionamos se os jovens da comunidade empregam a língua da mesma forma que os mais velhos. A pergunta era a seguinte: "Você acha que os jovens da comunidade falam de forma diferente ou igual aos mais velhos"? Vamos ver as respostas:

\begin{tabular}{|c|c|c|}
\hline Informantes & É igual & É diferente \\
\hline Abaixo de 45 anos & $(17)$ & $\begin{array}{c}(16)(19)(20)(21)(22)(23) \\
(24)\end{array}$ \\
\hline Entre 46 e 65 anos & & $\begin{array}{c}(1)(2)(7)(8)(9)(14)(15) \\
(18)\end{array}$ \\
\hline Acima de 66 anos & $(3)(5)(6)(11)$ & $(4)(10)(12)(13)$ \\
\hline Total: & 5 & 19 \\
\hline
\end{tabular}

Tabela 3: O falar dos jovens em relação ao dos mais velhos

Logo se vê que a grande maioria dos entrevistados percebe que os jovens não falam do mesmo jeito que os mais velhos. Todos os informantes da faixa etária 46-65 anos percebem as diferenças. Os motivos apontados foram maciçamente a escolaridade e o contato com as novas tecnologias. Assim, para eles:

Em certas ocasiões, em certo jeito sim, porque o jovem hoje em dia, como diz, eles nasceram na era da tecnologia, né? hoje em dia tá bem diferente, o progresso aumentou muito essas coisas de celular, de coisarada, então eu acho que eles têm uma maneira diferente de agi, de se manifestá, né, mas nada que seje contra (Informante 2, feminino, 59 anos).

Ah, os jovens já mudou muito, porque a maioria tão estudando e o estudo faz que vá mudando o tipo de falá (Informante 7, masculino, 59 anos).

O jovem, o adolescente tem uma coisa mais diferente de falá... querê falá mais certo, né, os idoso talvez por causa da idade falam um pouco diferente porque acha que é daquele jeito (Informante 21, feminino, 22 anos).

Eu vejo assim mais nas palavra erradas, a gente já percebe que os jovens já tão falando mais correto o português (Informante 23, feminino, 45 anos).

Diferente, até essas gírias dos mais jovens... os mais velhos têm um jeito próprio de falá (Informante 24, feminino, 28 anos).

A terceira e última pergunta relacionada ao que aos descendentes de italianos entrevistados acreditam em relação à língua que falam envolve a língua portuguesa: "Você acha que a língua portuguesa é fácil ou é difícil”? As respostas foram bem interessantes: 


\begin{tabular}{|c|c|c|}
\hline Informantes & A lingua portuguesa é fácil & A lingua portuguesa é dificil \\
\hline Abaixo de 45 anos & $(17)$ & $(16)(19)(20)(21)(22)(23)(24)$ \\
\hline Entre 46 e 65 anos & $(7)(8)(9)(15)(18)$ & $(1)(2)(14)$ \\
\hline Acima de 66 anos & $(4)(5)(6)(10)(11)(12)(13)$ & $(3)$ \\
\hline Total: & 13 & 11 \\
\hline
\end{tabular}

Tabela 4: Concepções acerca da língua portuguesa falada no Brasil

Os descendentes integrados na faixa etária superior a 46 anos acreditam que a língua portuguesa é fácil de falar, entender e escrever, principalmente quando comparada ao italiano. O que pudemos perceber com as ideias expostas pelos entrevistados mais jovens foi que ainda é muito forte a concepção de que a língua portuguesa "certa" é aquela estudada na escola, já que alguns deles deixaram claro que a língua falada na zona rural é "errada" e que quando eles se deparam com regras e detalhes da língua portuguesa, consideramna muito difícil.

Vamos elencar o que foi dito:

Eu acho que é mais difícil que o italiano que eu aprendi, né? não é tantas coisas num sentido, né? que a língua portuguesa tem uma coisa que é falada em quatro tipos, né? e a italiana tem um sentido só (Informante 1, feminino, 60 anos).

Eu não estudei muito, mais meus neto, meus filho acham que é difícil... por causa dos ponto que tem, né? (Informante 14, feminino, 63 anos)

Eu acho mais fácil até falá italiano do que português (Informante 16, feminino, 38 anos).

Depende do que tem que que fazê com ela... mas eu acho que pra nóis que tamo aqui no Brasil não é difícil, não, claro que tem os pormenores ali que a gente tem que conhecê, mas não é complicada, não (Informante 17, feminino, 31 anos).

Pra nóis que aprendimo a falá do nosso jeito pra nóis é fácil, mas agora pra quem vem de fora e fala outra língua pra eles aprenderem a falá em português... porque o português ele tem muito sinônimo, né? Então a mesma palavra tem vários significado então pra quem vai aprendê o português é difícil, mais pra nóis não é difícil (Informante 18, feminino, 55 anos). Ela é difícil porque ela tem um vocabulário imenso, ela tem conteúdos estruturantes, uma gramática que envolve... (...) eu considero pra ensinar no meu dia a dia o português pro meus alunos eu considero ela difícil, porque os meus alunos eles têm a cultura deles... eles escrevem, então se eles vão fazer uma produção de texto a cultura que eles vivem eles escrevem e eu não sou ninguém pra modificar a cultura deles, então eu tenho que acatá como certo, então eu acho o português difícil (Informante 20, feminino, 32 anos).

Super difícil... muitas normas e às vezes sem porque ter (Informante 22, feminino, 25 anos).

É uma das mais difícil... mais difícil que o italiano, eu posso te garanti... tanto na escrita quanto na fala... é muito difícil (Informante 23, feminino, 45 anos).

Agora veremos as três questões que exploram as atitudes linguísticas dos entrevistados. Sobre as atitudes quanto à língua italiana e seus falantes, interpelamos se os moradores do Pinho de Baixo comprariam imóvel em um bairro onde só morassem descendentes de ucranianos e poloneses. Nessa questão devemos ressaltar que a cidade de Irati foi colonizada principalmente por poloneses e ucranianos, e seus descendentes correspondem a boa parte da população da cidade. Averiguemos o que os entrevistados responderam:

\begin{tabular}{|c|c|c|}
\hline Informantes & Compraria & Não compraria \\
\hline Abaixo de 45 anos & $\begin{array}{c}(16)(17)(19)(20)(21)(22) \\
(23)(24)\end{array}$ & \\
\hline Entre 46 e 65 anos & $(1)(7)(8)(9)(14)(15)(18)$ & $(2)$ \\
\hline Acima de 66 anos & $(3)(5)(6)$ & $(4)(10)(11)(12)(13)$ \\
\hline Total: & 18 & 6 \\
\hline
\end{tabular}

Tabela 5: Possibilidade de adquirir imóvel em um bairro de descendentes de eslavos

Todos os entrevistados, 24, responderam a essa pergunta. Destas, dezoito asseguraram que comprariam tranquilamente uma casa em um lugar em que predominasse outra etnia, já que essa poderia ser também uma oportunidade de interagir e aprender outra cultura:

Ah, eu ia adorá... conversá, conhecê, tentá aprendê (...) eu acho assim que, independente das nossas etnias nós somos todos iguais, né, cada um com seu jeitinho, cada uma 
com sua habilidade, mas ia ser muito divertido (Informante 20, feminino, 32 anos).

Não faria diferença pra mim... acredito que se as pessoas forem boas e o bairro for seguro não faria diferença pra mim (Informante 22, feminino, 25 anos).

Os 06 informantes que garantiram que não morariam em um lugar povoado maciçamente por outra cultura admitiram ser a língua a principal barreira que impediria um bom relacionamento:

Não, porque a gente de repente não se enquadra com a língua porque polonês ensinam mais os filho a conversá em polonês e a nossa língua não (...) não que eu não aceito, só que a gente não vai se sentir bem num lugar que não dá pra entender... mas os polonês tão de parabéns, eles ensinam as crianças falá em polonês (Informante 4, feminino, 75 anos).

Eu acho meio difícil, né? Porque a língua deles já é mais puxada, né? (...) dificilmente a gente ia se acertá (Informante 10, masculino, 86 anos).

Não seria bom, né? Sempre o vizinho é aquele que cê tá se vendo tuda hora né? Aí cê imagine um bairro de ucraino por exemplo... se ele fala na língua dele você acha que ele tá falando mar de você e vice-versa se a gente também falá (...) eu sempre me segurei de não falá na minha língua, a língua italiana perto de gente que não entendesse por causa disso, a pessoa pode entender errado, né? (Informante 12, masculino, 76 anos)

Já a segunda pergunta, baseada em Balthazar (2016), consistia em: “Quando você tropeça em uma pedra ou alguma coisa dá errado, em que língua você xinga? Quais xingamentos você conhece em italiano?" Os informantes se divertiram muito com essa questão. Vejamos:

\begin{tabular}{|c|c|c|c|}
\hline Informantes & $\begin{array}{c}\text { Xinga em português } \\
\text { quando tropeça }\end{array}$ & $\begin{array}{c}\text { Xinga em italiano } \\
\text { quando tropeça }\end{array}$ & Não xinga \\
\hline Abaixo de 45 anos & $(20)(22)(23)(24)$ & $(16)(17)(19)(21)$ & \\
\hline Entre 46 e 65 anos & $(2)(9)(14)$ & $(1)(7)(8)$ & $(15)(18)$ \\
\hline Acima de 66 anos & $(5)(10)$ & $(3)(6)(12)$ & $(4)(11)(13)$ \\
\hline Total: & 9 & 10 & 5 \\
\hline
\end{tabular}

Tabela 6: Atitude de utilizar xingamentos na língua vernácula
Das três opções de resposta, podemos analisar na tabela 6 que xingar em italiano foi a opção vencedora:

Eu gostava de xingar em italiano meu veio, até hoje eu xingo meus piá em italiano (Informante 3, feminino, 90 anos).

Se a pedra for muito... machucar bastante eu digo nome em italiano memo" (Informante 8, masculino, 57 anos).

Os dois... o qual vié primeiro, mas mais em italiano (Informante 16, feminino, 38 anos).

Depende, se tivé com muita raiva vai em italiano... (Informante 17, feminino, 31 anos).

Por fim, perguntamos se "Você já tentou falar de forma chique com alguém? Em quais situações"? Das 24 pessoas que responderam a essa pergunta, 08 afirmaram terem monitorado a fala em alguma situação, ao passo que 16 declararam nunca terem tido esse comportamento. Vamos à tabela:

\begin{tabular}{|c|c|c|}
\hline Informantes & Já falou de forma monitorada & $\begin{array}{c}\text { Nunca falou de forma } \\
\text { monitorada }\end{array}$ \\
\hline Abaixo de 45 anos & $(17)(20)(22)$ & $(16)(19)(21)(22)(23)$ \\
\hline Entre 46 e 65 anos & $(1)(8)(14)(15)(18)$ & $(2)(7)(9)$ \\
\hline Acima de 66 anos & & $(3)(4)(5)(6)(10)(11)(12)(13)$ \\
\hline Total: & 8 & 16 \\
\hline
\end{tabular}

Tabela 7: Tentativa de fala monitorada em alguma situação comunicativa

Apesar de dados indicarem que os descendentes de italianos residentes no Pinho de Baixo têm uma forte consideração por sua fala e, por isso, prevalece o número daqueles que evitam camuflá-la, sabemos que, independente da língua ou da variedade linguística que utilizamos, sempre há situações em que precisamos nos adequar ao cenário em que estamos inseridos. Muitos informantes da nossa pesquisa são atuantes na comunidade, participam de eventos religiosos, festas e reuniões de cooperativas, e interagem com 
pessoas "mais estudadas", como eles mesmos afirmaram em outros momentos da pesquisa, o que implica em certo monitoramento linguístico.

Vejamos algumas respostas dadas pelos entrevistados:

Ih, se for falá chique a gente se embanana tudo, né? vai se atrapalhá mais ainda, né? (Informante 2, feminino, 59 anos).

Ah, eu falo do jeito que for. A gente querendo... se for falá, querê fala tudo chique assim você se atrapalha, né? (...) eu já conversei com jornalista, mas só falo assim, se for enfeitar no fim estraga tudo (Informante 6, masculino, 74 anos).

Não! Eu não mudo meu tipo de falar! (Informante 7, masculino, 59 anos).

Não, a gente não pode ser o que não é... a gente fala tal qual a natureza da gente... (Informante 10, masculino, 86 anos)

Não, eu acho que o mais certo é o normal, né? É aquilo que é (Informante 12, masculino, 76 anos).

Outras pessoas, por sua vez, apesar de também valorizarem o falar da região, julgam necessário fazer adequações, a depender do interlocutor:

Sim... se vem uma pessoa estudada, eu falo de um jeito, se for aqui da comunidade eu falo de outro (Informante 15, feminino, 65 anos).

Já! A gente quando chega assim perto de alguém que a gente sabe que tem mais conhecimento, né? a gente tenta não falá as palavra errada... que nem acostuma assim ca mãe e co pai que fala sempre errado em casa, ansim, a gente procura colocá uma palavra mais certa (Informante 17, feminino, 31 anos).

Com esse resultado, constata-se que mesmo situados em um contexto de transição, onde as atividades da cidade estão se alastrando cada vez mais para o campo, nossos entrevistados mantêm vivos os costumes e tradições herdados dos seus antepassados vindos da Itália.

\section{Considerações finais}

Neste estudo, pudemos interagir com uma realidade diferente da que estamos acostumados.
Nos deparamos com uma comunidade formada predominantemente por descendentes de italianos que vivem em um contexto de transição. Denominamos esse processo de transição devido ao fato de grande parte dos filhos de imigrantes já terem morrido e agora os netos e bisnetos têm se familiarizado com outras culturas, tirando o italiano do centro da comunidade.

Por meio das entrevistas que fizemos, percebemos um grande número de atitudes positivas em relação à língua falada pelos moradores do Pinho de Baixo. Essas mesmas atitudes também foram percebidas em relação à fala dos moradores de Irati e das comunidades vizinhas. Isso indica que nossos entrevistados não demonstram ser preconceituosos. Assim, nosso primeiro objetivo, que era analisar as crenças e atitudes linguísticas desses falantes, foi alcançado, pois conseguimos uma pequena, mas representativa, amostra dessa população.

Ao dividir os informantes em três faixas etárias, abaixo de 45 anos, entre 46 e 65 anos e acima de 66 anos, percebemos que há algumas diferenças nas concepções desses indivíduos acerca da língua, da cultura e das relações estabelecidas entre moradores da cidade e do campo. Constatamos que os informantes mais velhos têm deixado de lado algumas práticas como conversar e rezar em italiano, alegando terem esquecido as palavras ou não terem com quem conversar. Por outro lado, os informantes mais jovens têm se preocupado em resgatar a cultura dos antepassados por intermédio de atividades culturais, como o grupo folclórico, o museu e a tradicional Festa da Polenta.

\section{Referências}

AGUILERA, Vanderci de Andrade; SILVA, Hélen Cristina da. O poder de uma diferença: um estudo sobre crenças e atitudes linguísticas. Alfa, São Paulo, 58 (3): 703-723, 2014. Disponível em: http:// 
www.Scielo.Br/scielo.Php?Script=sci arttext\&pid=s1981-

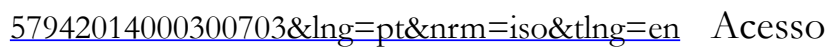
em 25 de abr de 2016.

ALKMIM, Tânia. Sociolinguística. Parte I. In.: MUSSALIM, Fernanda; BENTES, Anna Christina. Introdução à linguística: domínios e fronteiras. São Paulo: Cortez, 2001.

BACIL, Elizete. Capela São Sebastião: 100 anos de fé e religiosidade. Irati, 2012.

BAGNO, Marcos. Preconceito linguístico: o que é, como se far: São Paulo: Edições Loyola, 2007.

BALTHAZAR, Luciana. Atitudes linguísticas de italobrasileiros em Criciuma (SC) e região. Universidade Federal do Paraná, Curitiba, 2016. Tese de Doutorado.

BOTASSINI, Jacqueline Ortelan Maia. Crenças e atitudes linguísticas: um estudo dos róticos em coda silábica no norte do Paraná. Tese de doutorado. Universidade Estadual de Londrina. Londrina, 2013.

CALVET, Louis-Jean. Sociolinguistica: uma introdução crítica. São Paulo: Parábola, 2007.

CORBARI, Clarice Cristina. Crenças e atitudes linguisticas de falantes de Irati (PR). Signum: Estud. Ling., Londrina, n. 15/1, p. 111-127, jun. 2012. Disponível em: http://www.Uel.Br/revistas/uel/index. Php/signum/article/view/11378 Acesso em 25 de abr de 2016.

CYRANKA, Lucia Furtado de Mendonça. Atitudes Linguísticas de Alunos de Escolas Públicas de Juiz de Fora - MG. Niterói, 2007. Tese de Doutorado.

DIAS, Luiz Antônio Xavier. Crenças e atitudes linguísticas no uso dos róticos de professores e professorandos de Jacarezinho - PR. Fortaleza: Entrepalavras ano 4, v.4, n.2, p. 90-104, jul/dez 2014. ISSN 2237-6321.

LAMBERT, W. William; LAMBERT, E. Wallace. Psicologia Social. Rio de Janeiro: Zahar Editores, 1968.

MASSAROLLO, Ana Maria Bonk. Crenças e atitudes linguisticas: um estudo sociolinguistico sobre o contato linguístico em Santo Antônio do Sudoeste/Brasil. Anais do X Encontro do CELSUL - Círculo de Estudos Linguísticos do Sul UNIOESTE - Universidade Estadual do Oeste do Paraná Cascavel-PR. ISSN 2178-775. 2012.

MOLLICA, Maria Cecília. Linguagem para formação em Letras, Educação e Fonoaudiologia. São Paulo: Contexto, 2009.

MONTEIRO, José Lemos. Para compreender Labov. Petrópolis, Rio de Janeiro: Vozes, 2000.

ORLANDI, Eni Pulcinelli. O que é Linguística. São Paulo: Brasiliense, 2007.

SILVA, Rita do Carmo Polli. A Sociolinguistica e a lingua materna. Curitiba: IBEPEX, 2009.

SOUZA, Elizete Cristina de. Crenças e atitudes de professores e alunos no Brasil e na Espanha, sobre variação linguística. Brasília, 2012.

TARALLO, Fernando. A pesquisa sociolinguística. $3^{\mathrm{a}}$ Ed. São Paulo: Editora Ática, 1990.

Recebido em 30 de março de 2017 Aprovado em 20 de agosto de 2017 